\title{
Papers
}

\section{Ethnographic study of incidence and severity of intravenous drug errors}

\author{
Katja Taxis, Nick Barber
}

\begin{abstract}
Objectives To determine the incidence and clinical importance of errors in the preparation and administration of intravenous drugs and the stages of the process in which errors occur.

Design Prospective ethnographic study using disguised observation.

Participants Nurses who prepared and administered intravenous drugs.

Setting 10 wards in a teaching and non-teaching hospital in the United Kingdom.

Main outcome measures Number, type, and clinical importance of errors.

Results 249 errors were identified. At least one error occurred in 212 out of 430 intravenous drug doses ( $49 \%, 95 \%$ confidence interval $45 \%$ to $54 \%)$. Three doses (1\%) had potentially severe errors, $126(29 \%)$ potentially moderate errors, and $83(19 \%)$ potentially minor errors. Most errors occurred when giving bolus doses or making up drugs that required multiple step preparation.

Conclusions The rate of intravenous drug errors was high. Although most errors would cause only short term adverse effects, a few could have been serious. A combination of reducing the amount of preparation on the ward, training, and technology to administer slow bolus doses would probably have the greatest effect on error rates.
\end{abstract}

\section{Introduction}

Intravenous therapy is a complex healthcare technology. In the United Kingdom, as in most other European countries, nurses generally prepare and administer intravenous drugs prescribed by doctors. Administration of intravenous therapy is associated with considerable risk-for example, patients have died when cytotoxic drugs have been given intrathecally instead of intravenously. ${ }^{1}$ The UK Department of Health has made this particular type of error one of its prime targets in increasing patient safety. ${ }^{2}$ Similar initiatives have been proposed in the United States. ${ }^{3}$

Little prospective research has been done into the incidence, causes, and severity of intravenous drug errors. Single site studies carried out on one or two wards have reported errors in preparing and administering intravenous drugs of $13 \%-84 \%,{ }^{4-7}$ but the studies used different definitions and did not assess the sever- ity of errors. Epidemiological studies using retrospective record review have shown that adverse drug events are common but have not provided detailed analysis of the type of errors. ${ }^{8-11}$ We therefore conducted an ethnographic prospective study using defined measures to determine the incidence of errors in preparing and administering intravenous drugs, to identify the stages in the process in which errors occur, and to evaluate their clinical importance.

\section{Participants and methods}

We used a purposive sampling strategy to select study hospitals and study wards, with the aim of exploring the preparation and administration of intravenous drugs in a range of settings. We selected a university teaching hospital and a non-teaching general hospital of similar size (about 20 wards and 400 beds). We did a pilot study to determine the frequency of use of intravenous drugs on each ward and then selected a total of 10 wards with high, medium, and low usage.

Both hospitals operated a typical British ward pharmacy service. Doctors recorded prescriptions on formatted inpatient drug charts, and nurses used the charts to determine the doses due and record the administration of drugs. Ward pharmacists ordered drugs that were not stored on the ward and reviewed the appropriateness of prescribed drugs every weekday. Nurses usually prepared and administered intravenous drugs on the wards, but cytotoxic drugs were prepared centrally by the pharmacy department. Nurses had to attend a one day training course before they were allowed to give intravenous drugs. A guide to preparation and administration of intravenous drugs was available on each ward.

\section{Identification of errors}

We defined an intravenous drug error as a deviation in preparation or administration of a drug from a doctor's prescription, the hospital's intravenous policy, or the manufacturer's instructions. The clinical appropriateness of the prescription was not assessed. All errors had to have the potential to adversely affect the patient, so deviations from hospital procedures, such as not checking name bands or not labelling infusions, were not considered as errors if the correct drug was given to the patient. Deviations from prescribed administration time were not considered errors. We excluded errors if they were corrected by a member of
Department of Practice and Policy, School of Pharmacy, Pharmacy, London, London London, Lon
WC1 1AX

Katja Taxis

assistant professor in pharmacy

Nick Barber professor of the practice of pharmacy

Correspondence to: K Taxis,

Pharmazeutische Biologie,

Pharmazeutisches Institut, Universität Tübingen, Auf der Morgenstelle 8, 72076 Tübingen, Germany katja.taxis@ uni-tuebingen.de

bmj.com 2003;326:684 
staff or the patient before administration. Errors were related to particular actions; multiple errors could occur in each case of preparation and administration.

We chose a prospective ethnographic research method to collect data. A trained and experienced observer (KT) accompanied nurses during intravenous drug rounds. She recorded the preparation and administration of each drug on a standard form. Information came from observation and talking informally to staff. The researcher intervened in a discreet and non-judgmental manner when she became aware of a potentially serious error; these incidents were still included as an error. Ward staff were told that we were investigating common problems of preparing and administering intravenous drugs; this disguised observation method has been shown to be valid. ${ }^{12}$ The researcher avoided the word error to prevent the study from appearing threatening to staff. Each nurse gave permission for observation.

Data were collected on 6-10 consecutive days on each ward between June 1999 and December 1999. To be representative, the study included weekends and all times of drug rounds on each ward. The researcher attended two to three drug rounds out of the four that took place each day.

\section{Importance of errors}

We used a validated scale to assess the clinical importance of intravenous drug errors. ${ }^{13}$ Briefly, four experienced healthcare professionals (one doctor, one nurse, and two pharmacists) scored the potential clinical importance of each drug error on a visual analogue scale between zero (labelled as no harm) and 10 (death). The mean score was calculated for each drug error. Mean scores below 3 suggested a minor outcome, scores of 3-7 a moderate outcome, and scores above 7 a severe outcome.

\section{Analysis of data}

The data on the incidence of intravenous drug errors is expressed in two ways: errors per dose and errors per process stage (boxes 1 and 2). KT classified the errors and NB checked them. We calculated proportions and $95 \%$ confidence intervals using standard methods. ${ }^{14}$

\section{Results}

A total of 113 nurses and one doctor were observed over 76 days (table 1 ). Table 2 shows the number of

Box 1: Classification of intravenous drug errors according to stage of occurrence (categories are mutually exclusive)

Preparation stage

Identification of prescription

Preparation process:

Ready for administration

One step preparation, eg measuring a drug solution

Multiple step preparations, eg measuring and

diluting a drug solution, reconstitution of a drug

\section{Administration stage}

Identification of the patient

Administration process:

Bolus dose injection, usually 3 to $5 \mathrm{~min}$

Intermittent infusion

Continuous infusion
Box 2: Classification of type of intravenous drug errors (categories are mutually exclusive)

\section{Preparation errors}

Preparation of wrong drug

Preparation of an unauthorised drug

Errors in solvent/diluent (use of wrong

solvent/diluent or wrong volume)

Preparation of wrong dose

Omission of prescribed drug

Other

\section{Administration errors}

Administration to wrong patient

Fast administration of bolus dose through a peripheral line

Fast administration of bolus dose through a central line

Incompatibility errors

Other

Table 1 Position of staff included in the study

\begin{tabular}{lc} 
Staff grade & No of observations \\
\hline Staff nurse & 280 \\
\hline Ward manager/sister & 73 \\
\hline Bank/agency nurse & 62 \\
\hline Student nurse & 11 \\
\hline Doctor & 4 \\
\hline Total & 430 \\
\hline
\end{tabular}

observations on each ward. All the nurses agreed to participate. On three occasions ward managers asked the researcher not to observe a particular drug round as the general workload on the ward was high. Altogether 1042 doses of intravenous drugs, representing 35 different drugs, were prescribed for 106 patients during the study. Our observations were representative for the study period: $41 \%$ (430) of all intravenous drug doses prescribed were observed; administrations of $91 \%$ (32) of the prescribed drugs was observed at least once; and 92\% (98) of patients who were prescribed regular intravenous drugs were observed at least once. The researcher intervened in 12 cases to prevent an error reaching the patient.

One or more errors occurred in the preparation and administration of 212 out of 430 intravenous drug doses (error rate 49\%, 95\% confidence interval $45 \%$ to

Table 2 Number of observations by type of ward

\begin{tabular}{lc} 
Type of ward & No of observations \\
\hline University teaching hospital: & \\
\hline General medical ward & 41 \\
\hline Renal ward & 41 \\
\hline Cardiothoracic surgical ward & 42 \\
\hline Coronary intensive care unit & 67 \\
\hline Neonatal ward & 29 \\
\hline Oncology ward & 33 \\
\hline Non-teaching hospital*: & \\
\hline General surgical ward & 64 \\
\hline General medical ward & 58 \\
\hline Intensive care unit & 39 \\
\hline Paediatric ward & 16 \\
\hline Total & 430 \\
\hline${ }^{*}$ Former district general hospital.
\end{tabular}


54\%). A total of 249 errors were identified. Preparation errors occurred in 32 intravenous doses (7\%), administration errors in 155 doses $(36 \%)$, and both types of error in 25 doses $(6 \%)$. Errors were potentially severe in three doses $(1 \%)$, potentially moderate in $126(29 \%)$, and potentially minor in $83(19 \%)$. Box 3 describes the three severe errors and typical examples of moderate and minor errors.

The figure shows the incidence of errors at each stage of drug preparation and administration. Most preparation errors were associated with multiple step preparations-for example, drugs that required reconstitution with a solvent and addition of a diluent. Typical errors were preparing the wrong dose or selecting the wrong solvent. All three severe errors occurred at this stage. A few errors occurred in identifying prescriptions-for example, not seeing a drug order. Most errors occurred when giving bolus doses, with errors in 172/235 (73\%) doses. In most of these cases $(163,95 \%)$ the dose was given faster than recommended, which is usually three to five minutes; more than half of these errors $(85,52 \%)$ were considered to be of potential moderate severity. Table 3 gives a more detailed analysis of the type and severity of the errors.

\section{Discussion}

We found a high incidence of errors in the preparation and administration of intravenous drugs. Although most were unlikely to cause lasting harm, some were serious. The sample was taken from two types of hospital and included a range of patients, nurses, drugs, drug administration times, ward specialties, and frequency of drug administration on the ward. We have used explicit methods, definitions, and tools that we hope others can use elsewhere for research and audit.

Although the proportion of serious errors is small, the number of patients and intravenous doses in a hospital means that errors may be more common than expected. A point prevalence study we carried out in the university teaching hospital (400 beds) showed that about 112 (28\%) of inpatients received intravenous drugs, resulting in more than 300 doses a day. Although we cannot extrapolate with any precision, our data suggest that at least one patient will experience a potentially serious intravenous drug error every day in a hospital of that size. Hence, intravenous drug errors are a potential source of serious harm for patients and risk reduction strategies should be developed accordingly.

\section{Reducing the risks}

Our analysis shows that the two weak stages in the system are drugs that require multiple step preparation and administration of doses as a bolus. Several strategies could be used to reduce multiple step preparation errors. Centralised preparation of intravenous drugs by the pharmacy department was suggested in the 1970s in the United Kingdom but was rarely adopted..$^{15}$ Centralised preparation of intravenous drugs is common in the United States ${ }^{16}$ but not in Europe, apart from in specialised areas such as oncology. ${ }^{17}$ The evidence for centralised services is currently weak, and it is unclear whether they are cost effective or improve the quality of the service. ${ }^{18-21}$ An alternative strategy would be to purchase ready

\section{Box 3: Examples of intravenous drug errors}

\section{Potentially severe errors}

- The whole content of a vial containing 125000 international units of heparin was prepared as a continuous infusion, resulting in a five times overdose (severity score 8.4; general medical ward, teaching hospital). Comment: Haemorrhage is one of the serious, potentially life threatening complication of an overdose of heparin.

- A nurse injected $750 \mathrm{mg}$ vancomycin into an infusion bag of $0.9 \%$ sodium chloride (already connected to the patient's cannula) without mixing the solution. The patient is likely to have initially received a concentrated solution of vancomycin as a bolus (severity score 7.3; renal ward, teaching hospital). Comment: Rapid infusions of vancomycin carry the risk of reactions such as severe hypotension (including shock and cardiac arrest) and flushing of the upper body.

- A patient's continuous infusion of adrenaline (epinephrine) was interrupted for about 10 minutes as the new infusion had not been prepared in advance (severity score 7.5 ; intensive care unit, non-teaching hospital). Comment: This patient's blood pressure decreased to about 50/30 $\mathrm{mm} \mathrm{Hg}$. A bolus dose of adrenaline and midazolam was given to stabilise him until the adrenaline infusion was restarted.

\section{Potentially moderate errors}

- A nurse measured $0.2 \mathrm{mg}$ metoclopramide using a $1 \mathrm{ml}$ syringe and then drew up $0.9 \%$ sodium chloride into the same syringe. This was administered as a bolus dose. Using this preparation technique, the metoclopramide contained in the dead space of the syringe (hub and needle) was also administered to the patient, resulting in a two to three times overdose (severity score 7.0; neonatal ward, teaching hospital). Comment: Side effects include extrapyramidal effects, which are more likely in children. There are also reports of cardiac conduction abnormalities.

- A patient's lunchtime dose of $750 \mathrm{mg}$ cefuroxime was omitted because of his transfer to another ward at lunchtime (severity score 4.1; cardiothoracic surgical ward, teaching hospital). Comment: Successful anti-infective therapy depends on achieving effective levels.

- Administration of $80 \mathrm{mg}$ furosemide (frusemide) over 45 seconds through a peripheral vein (severity score 6.1 ; general surgical ward, non-teaching hospital). Comment: The recommended duration of administration was $20 \mathrm{~min}$ ( $4 \mathrm{mg} / \mathrm{min})$. Tinnitus and deafness are among the side effects reported after rapid administration.

\section{Potentially minor errors}

- Preparation of $1.2 \mathrm{~g}$ co-amoxiclav using $10 \mathrm{ml}$ instead of $20 \mathrm{ml}$ water for injection (severity score 2.3; general surgical ward, non-teaching hospital). Comment: The drug may not dissolve completely when insufficient solvent is used. Concentrated solutions may also increase the risk of thrombophlebitis.

- Administration of $500 \mathrm{mg}$ amoxycillin/10 ml of water by injection over 2.5 minutes rather than through a peripheral vein over 3-5 minutes (severity score 2.9; general medical ward, teaching hospital). Comment: More rapid administration may damage the blood vessels but is unlikely in this case.

prepared intravenous drugs from pharmaceutical companies.

The effect of the above changes would have to be assessed carefully. New types of errors could be

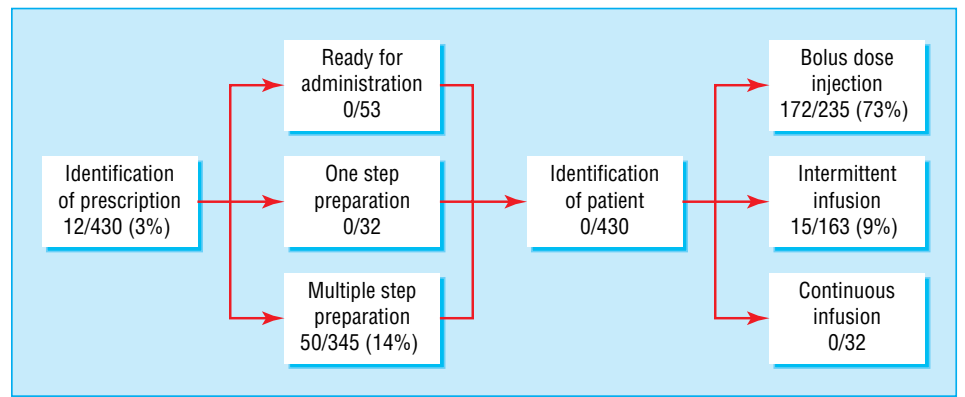

Stages and errors in preparation and administration of intravenous drugs (numbers of errors/number of observations of each stage) 
Table 3 Type and clinical importance of errors in preparation and administration of intravenous drugs. Values are numbers (percentages) of errors in 430 observations

\begin{tabular}{lcccc} 
& \multicolumn{3}{c}{ Importance of error } & \multirow{2}{*}{ Total } \\
\cline { 2 - 4 } Type of error* & Minor & Moderate & Severe & \\
\hline Preparation errors: & & & & $36(8)$ \\
\hline Errors in solvent/diluent & $20(5)$ & $16(4)$ & 0 & $12(3)$ \\
\hline Wrong dose & 0 & $11(3)$ & $1(0.2)$ & $12(3)$ \\
\hline Omission & 0 & $12(3)$ & 0 & $2(0.5)$ \\
\hline Other & 0 & 0 & $2(0.5)$ & \\
\hline Administration errors: & & & & $127(30)$ \\
\hline Fast bolus dose (peripheral line) & $64(15)$ & $63(15)$ & 0 & $36(8)$ \\
\hline Fast bolus dose (central line) & $14(3)$ & $22(5)$ & 0 & $12(3)$ \\
\hline Incompatibilities & $1(0.2)$ & $11(3)$ & 0 & $12(3)$ \\
\hline Other & $3(7)$ & $9(2)$ & 0 &
\end{tabular}

${ }^{*}$ No errors were observed in the categories of preparing the wrong drug, using an unauthorised drug, or administration to the wrong patient.

introduced, such as transmission errors from the ward to the preparation department. ${ }^{22}$ Furthermore, nurses who are no longer used to preparing intravenous drugs may make serious errors if they have to prepare drugs in an emergency.

Technical solutions could reduce the frequent errors from rapid bolus injections-for example, a pump that prevents fast administration of bolus doses. Staff training could improve awareness of drugs that have a high risk of adverse effects when given too fast. A warning could also be put on the drugs by the pharmacy.

\section{Validity of study}

The effect of the observer on the observed is often discussed as a possible limitation of ethnographic observation methods. ${ }^{23}$ The error rate may be even higher in the absence of the researcher. However, a previous observation based study using a similar method showed that the drug error rate is unlikely to be affected by the observer, even if the observer occasionally intervenes. ${ }^{12}$ Modification of behaviour is minimal once the researcher is an accepted member of the group and part of the social context. ${ }^{24}$ The researcher seemed to have been accepted in our study, and some initial activities by nurses, such as wearing gloves to make up the doses, were soon abandoned. Using an observation based approach allowed us to explore drugs errors that would not have been documented and therefore missed by studies relying on review of hospital records. ${ }^{8}{ }^{11}$

\section{Conclusions}

Our study shows that errors in the preparation and administration of intravenous drugs remain a concern in the United Kingdom, 25 years after the problem was first highlighted. Steps to ensure the correct administration of bolus doses and to reduce mistakes in making up drugs that require multiple step preparation will have the greatest effect on error rates.

We thank the staff of the two participating hospitals.

Contributors: KT and NB designed the study and wrote the paper. KT collected the data and was responsible for data analysis. KT and NB are guarantors.

Funding: School of Pharmacy, University of London. The guarantors accept full responsibility for the conduct of the study, had access to the data, and controlled the decision to publish.

Competing interests: None declared.

Ethical approval: The ethics committees of the participating hospitals approved the study.

\section{What is already known on this topic}

Errors in preparing and administering intravenous drugs can cause considerable harm to patients

Reduction of drug errors is a government health target in the United Kingdom and the United States

\section{What this study adds}

Errors occurred in about half of the intravenous drug doses observed

Errors were potentially harmful in about a third of cases

The most common errors were giving bolus doses too quickly and mistakes in preparing drugs that required multiple steps

Dyer C. Doctors cleared of manslaughter. BMJ 1999;318:148.

2 Department of Health. Building a safer NHS for patients. London: Stationery Office, 2001.

Institute of Medicine Committee on the Quality of Health Care in America. To err is human. Washington: National Academy Press, 2000.

4 Thur MP, Miller WA, Latiolais CJ. Medication errors in a nurse-controlled parenteral admixture program. Am J Hosp Pharm 1972;29:298-304.

5 Hartley GM, Dhillon S. An observational study of the prescribing and administration of intravenous drugs in a general hospital. Int J Pharm Pract 1998:6:38-45.

6 O'Hare MCB, Gallagher T, Shields MD. Errors in the administration of intravenous drugs. BMJ 1995;310:1536-7.

Clark CM, Bailie GR, Whitaker AM, Goldberg LA. Parenteral drug delivery-value for money? Pharm J 1986;236:453-5.

Brennan TA, Leape LL, Laird N, Herbert L, Localio AR, Lawthers AG, et al. Incidence of adverse events and negligence in hospitalized patients. NEngl J Med 1991;324:370-6.

9 Leape LL, Brennan TA, Laird N, Lawthers AG, Localio AR, Barnes BA, et al. The nature of adverse events in hospitalized patients. $N$ Engl J Med 1991;324:377-84

10 Wilson RM, Runciman WB, Gibberd RW, Harrison BT, Newby L, Hamilton JD. The quality in Australia health care study. Med J Aust $1995 ; 163: 458-71$

11 Vincent C, Neale G, Woloshynowych M. Adverse events in British hospitals: preliminary retrospective record review. BMJ 2001;322:517-9.

12 Dean B, Barber N. Validity and reliability of observational methods for studying medication administration errors. Am J Health Syst Pharm 2001;58:54-9.

13 Dean BS, Barber ND. A validated, reliable method of scoring the severity of medication errors. Am J Health Syst Pharm 1999;56:57-62.

14 Gardner MJ, Altman DG. Statistics with confidence. London: BMJ Publications, 1989 .

15 Department of Health and Social Security. Report of the working party on the addition of drugs to intravenous infusion fluids (Breckenridge report). London: DHSS, 1976

16 Brzozowski DF, Hale KM, Segal R, Mirtallo JM. Pharmacists' opinion about and compliance with recommendations for intravenous admixture practices. Am J Health Syst Pharm 1987;44:2077-84.

17 Delaney T. EAHP survey of hospital-based pharmaceutical services in Europe, 1995. Eur Hosp Pharm 1996;2:92-105.

18 Armour DJ, Cairns CJ, Costello I, Riley SJ, Davies EG. The economics of a pharmacy-based central intravenous additive service for pediatric patients. PharmacoEconomics 1997;10:386-94

19 Chan R, Ryan M, Moriarty S, Feely J, Sabra K. The impact of a centralized reconstitution of intravenous additives service on administration times of intravenous antibiotics. Eur J Hosp Pharm 1993;3:93-5.

20 Cousins DH, Lee M, Stanaway M, Neary C. Implementation and evaluation of a centralised IV additive service for antibiotic injections. Pharm J 1989;242:HS14-6.

21 Wilson M. An evaluation of the cost effectiveness of a centralised intravenous admixture service. Proc Guild 1990;27:3-11.

22 Allan Flynn E, Pearson RE, Barker KN. Observational study of accuracy in compounding iv admixtures at five hospitals. Am J Health Syst Pharm 1997;54:904-12

23 Mays N, Pope C. Observational methods in health care settings. BMJ 1995;311:182-4.

24 Weick KE. Systematic observational methods. In: Lindzey G, Arouson F eds. The handbook of social psychology. Reading: Addison-Wesley, 1968:357421.

(Accepted 30 January 2003) 